\title{
An analytical model for the prediction of hot roll temperatures in a hot rolling process
}

\section{Vorhersage der Warmwalztemperatur in einem Warmwalzprozess durch ein analytisches Modell}

\begin{abstract}
V. Velay ${ }^{1}$, A. Michrafy ${ }^{2}$
Temperature variations in the hot roll during a hot rolling process were analysed by solving heat conduction equations for boundary conditions using an analytical method. The analysis was conducted in a steady-state regime, taking into account the effects of process parameters such as the contact surface, roll velocity and various cooling boundary conditions. Assuming the periodicity of the process, the development of a solution in the Fourier series was employed to solve the governing equations. The temperature and its gradient distributions in the roll depth were analytically expressed according to the process parameters. The accuracy of the predicted results was examined through comparison with predictions presented in the literature (finite element solutions and measurements). Results showed that an increase in the rolling speed leads to a shorter contact time, which decreases the temperature field in the work-roll.
\end{abstract}

Keywords: Hot rolling process / thermal transfer / process parameters

Schlüsselwörter: Warmwalzprozess / Wärmeübergang / Prozessparameter

\section{Introduction}

The hot rolling process is an important industrial process for manufacturing sheets with the appropriate mechanical properties. In this process, the workrolls are subjected to severe and periodic thermal loading during contact with the hot strip [1]. The repeated thermal cycles are responsible for the failures observed on the roll surface [2-7]. These failures are essentially a consequence of the thermal gradient, resulting from the heat transfer in the contact zone between the strip, where the temperature can reach $1273 \mathrm{~K}\left(1000^{\circ} \mathrm{C}\right)$, and the external cooling condi-

\footnotetext{
1 Université de Toulouse - CNRS, Mines-Albi, INSA, UPS, ISAE-SUPAERO; ICA (Institut Clément Ader), Campus Jarlard - 81013 Albi - Cedex 09 - France

2 Laboratoire de Génie des Procédés des Solides Divisés - UMR CNRS 2392, Ecole des Mines d'AlbiCarmaux, Campus Jarlard - 81013 Albi Cedex 09 France
}

tions applied on the roll [8]. In addition to the difference in temperature between the strip and the roll, plastic strains generated by pressure applied by the roller and frictional conditions required for successful hot rolling cause a rise in the temperature at the contact surface $[9,10]$. The changing conditions of heating and cooling operations are of considerable importance, since they reduce the lifetime of the work-roll, which is continuously subjected to thermal gradients generating high thermal stresses. Figure 1 summarizes the various heat flows generated in a hot rolling process from the heat exchange in the contact zone between the strip and the roll and the heat lost by air or water spray cooling. With the aim of increasing the lifetime of the roll, it is essen-

Corresponding author: Vincent Velay, Université de Toulouse - CNRS, Mines-Albi, INSA, UPS, ISAESUPAERO; ICA (Institut Clément Ader), Campus Jarlard - 81013 Albi - Cedex 09 - France, E-Mail: vincent.velay@ mines-albi.fr 


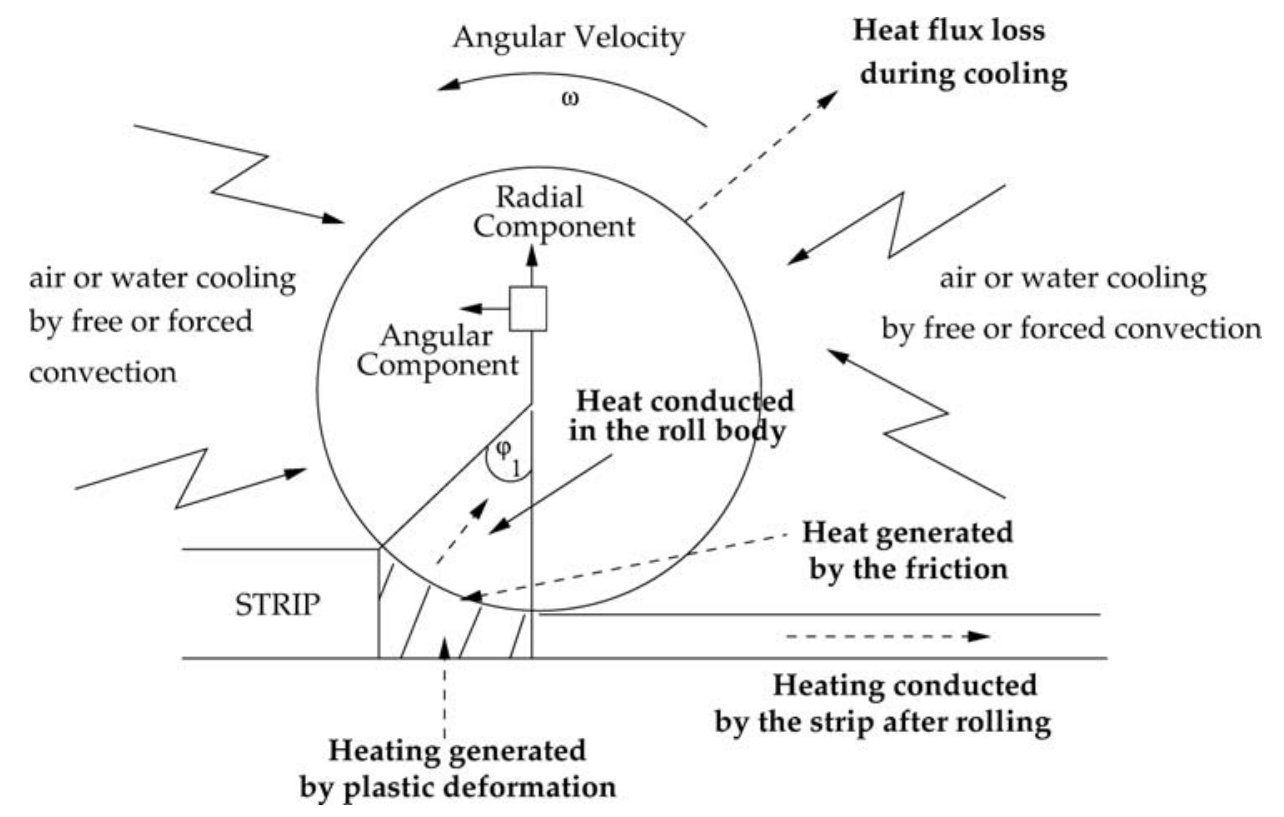

Figure 1. Various heat fluxes induced in the rolling process

tial to know the temperature distribution in the workroll during the hot rolling process. Several studies have been conducted to calculate temperature distribution in the work-roll using numerical, semi-analytical and analytical techniques [11-17]. The main advantage of the finite element method is to solve the governing heat-conduction equations for both the strip and the work-roll simultaneously [14, 18]. However, this technique requires fine meshes near the contact zone and hence high CPU time, which makes it difficult to use as an on-line process control method.

In contrast, the analytical solution seems to be more suitable for providing closed form equations for the temperature field and thermal stresses which compute very efficiently [12].

In this investigation, the contact between the roll and the strip is assumed perfect and the heat transfer generated by both plastic deformation of the strip and by friction is taken into account through a global contact temperature. Unlike several other studies the strip is not explicitly considered and the analysis of the heat transfer is focused only on the roll $[9,10$, 19-21]. The analysis is based on the temperature of the contact surface, the process parameters, such as the angular velocity $\omega$, the entry thickness of the strip - which corresponds to the $\varphi_{1}$ angle - and various cooling boundary conditions denoted by the $\varphi_{2}$ angle.
The objective of this work is to develop a semianalytical formulation of the heat transfer in the roll during the hot rolling process with accurate and appropriate time computation. In addition, this development could be used as a predictive tool for the optimization of the hot rolling process. The type of solution will strongly depend on the process parameters considered (cooling conditions, angular velocity of rotation) [22-24].

\section{Heat equation and boundary conditions}

The heat transfer equation in the roll during hot rolling is described by Eq. (1).

$\frac{\mathrm{d} T}{\mathrm{~d} t}=a \Delta T$

where $a=\frac{\lambda}{\rho C_{\mathrm{p}}}$ is the thermal diffusivity and $\lambda, \rho$ and $C_{\mathrm{p}}$ are respectively the thermal conductivity, the density and the specific heat of the material.

The stationary state leads to the following relation:

$\frac{\mathrm{d} T}{\mathrm{~d} t}=\frac{\partial T}{\partial \varphi} \dot{\varphi}=\frac{\partial T}{\partial \varphi} \omega$ 
Thus, the assumption of Eq. (2) combined with Eq. (1) expressed in a polar coordinate system provides the following relation:

$\frac{\partial^{2} T}{\partial \xi^{2}}+\frac{1}{\xi^{2}} \frac{\partial^{2} T}{\partial \varphi^{2}}+\frac{1}{\xi} \frac{\partial T}{\partial \xi}-\frac{\omega R^{2}}{a} \frac{\partial T}{\partial \varphi}=0$

The temperature field will depend on the angle $\varphi \in[0,2 \pi]$ and a dimensionless radius $\xi \in[0,1]$, defined as the ratio between $r$ and the radius of the roll $R$, with $0 \leq r \leq R$. Various boundary conditions are considered along thesurface of the roll. They can greatly influence the temperature field within the body of the roll. On the first part, delimited by angle $\varphi_{1}$, an applied temperature is considered (Dirichlet condition), which reproduces the temperature of the strip. Consequently, the angle $\varphi_{1}$ is considered as the contact arc length between the roll and the strip. On the remaining part of the roll, different cooling conditions can be applied (Neumann boundary conditions). For instance, the roll can be cooled by water or by air jet. Depending on the industrial process, these kinds of cooling can occur separately, or both of them may be be used in conjunction. In this last case, another angle $\varphi_{2}$ is introduced to define the part of the roll surface cooled by water jet and the part cooled by air jet.

Finally, both boundary conditions (Dirichlet and Neumann conditions) can be illustrated as:

$\xi=1 ; \quad \beta(\varphi) \frac{\partial T}{\partial \xi}+T-\theta(\varphi)=0$

where:

$\beta(\varphi)=\left\{\begin{array}{lll}0 & \text { if } & 0 \leq \varphi \leq \varphi_{1} \\ \frac{\lambda}{R h(\varphi)} & \text { if } & \varphi_{1} \leq \varphi \leq 2 \pi\end{array}\right.$

and:

$\theta(\varphi)=\left\{\begin{array}{lll}\theta_{1} & \text { if } & 0 \leq \varphi \leq \varphi_{1} \\ \theta_{2}(\varphi) & \text { if } \quad \varphi_{1} \leq \varphi \leq 2 \pi\end{array}\right.$

$\theta_{1}$ is the applied temperature, selected so as to be close to the strip temperature. $\theta_{2}(\varphi)$ is the temperature of the cooling fluid (water or air). Its value is constant if only one kind of cooling is considered, but it can evolve with $\varphi, \varphi_{1} \leq \varphi \leq 2 \pi$ if several kinds of cooling are applied. The thermal exchange coefficient is represented by $h(\varphi)$. Its value will strongly depend on the cooling conditions (fluid and rate).

\section{Temperature as Fourier series development}

The periodicity aspect of problems (3) and (4) requires us to seek the solution as a development of the Fourier series [25, 26]. The temperature field can be then written as:

$T(\xi, \varphi)=\sum_{\mathrm{n}=-\mathrm{N}}^{\mathrm{N}} T_{\mathrm{n}}(\xi) \mathrm{e}^{i n \varphi}$

where:

$T_{\mathrm{n}} \in \mathbb{C} \quad$ and $\quad T_{-\mathrm{n}}=\overline{T_{\mathrm{n}}}$

$\overline{T_{\mathrm{n}}}$ is the conjugate of $T_{\mathrm{n}}$

$i$ is such that $i^{2}=-1$

and $N \rightarrow \infty$.

In fact, the numerical implementation requires an integer value for $N$. This point will be discussed later in the paper.

Introducing Eq. (5) into Eq. (2) and considering all the terms of the Fourier series, the following equations are obtained:

$\frac{\partial^{2} T_{\mathrm{n}}}{\partial \xi^{2}}+\frac{1}{\xi} \frac{\partial T_{\mathrm{n}}}{\partial \xi}-\left(\frac{n^{2}}{\xi^{2}}+\frac{\mathrm{i}}{\varepsilon_{\mathrm{n}}^{2}}\right) T_{\mathrm{n}}=0$

where:

$\frac{1}{\varepsilon_{\mathrm{n}}}=R \sqrt{\frac{n \omega}{a}} \quad \forall n= \pm 1, \ldots, \pm \mathrm{N}$

It is obvious that the solution of the ordinary differential Eq. (6) is provided through a Bessel function $J_{\mathrm{n}}$ of the first kind of order $n$. Indeed, the function $T_{\mathrm{n}}(\xi)$ can be written as:

$T_{\mathrm{n}}(\xi)=A_{\mathrm{n}} J_{\mathrm{n}}\left(\frac{\xi(1-\mathrm{i})}{\sqrt{2} \varepsilon_{\mathrm{n}}}\right)$

where $A_{\mathrm{n}}$ is a constant. 
Moreover, an asymptotic expression of the Bessel function leads to the following form of the equation [27]:

$T_{\mathrm{n}}(\xi)=\frac{\tau_{\mathrm{n}}}{\xi} \mathrm{e}^{\frac{(1+\mathrm{i})(\xi-1)}{\sqrt{2} \varepsilon_{\mathrm{n}}}}$

where: $\tau_{\mathrm{n}} \in \mathbb{C}$ and its conjugate $\overline{\tau_{\mathrm{n}}}=\tau_{-\mathrm{n}}$.

Hence, the computation of $T_{\mathrm{n}}$ results from the determination of $\tau_{\mathrm{n}}$. Representing $\beta(\varphi)$ and $\theta(\varphi)$ (see Eq. (4)) in terms of the Fourier series:

$\beta(\varphi)=\sum_{n=-N}^{N} \beta_{n} e^{i n \varphi} ; \quad \theta(\varphi)=\sum_{n=-N}^{N} \theta_{n} \mathrm{e}^{i n \varphi}$

and including Eq. (8) into the boundary condition Eq. (4), we obtain the Eq. (9) that includes the boundary conditions.

$\sum_{\mathrm{j}=-\mathrm{N}+\mathrm{n}}^{\mathrm{N}+\mathrm{n}} \beta_{\mathrm{j}} \frac{\partial T_{\mathrm{n}-\mathrm{j}}}{\partial \xi}+T_{\mathrm{n}}-\theta_{\mathrm{n}}=0 ; \quad \xi=1$

$\forall n=0, \pm 1, \ldots, \pm N$

Then, using Eq. (7) in the previous Eq. (9), the following form can be found:

$$
\begin{aligned}
& \left.\sum_{\mathrm{j}=-\mathrm{N}+\mathrm{n}}^{\mathrm{n}-1} \tau_{\mathrm{n}-\mathrm{j}} \beta_{\mathrm{j}} \frac{1+\mathrm{i}}{\sqrt{2} \varepsilon_{\mathrm{n}-\mathrm{j}}}-\frac{1}{2}\right) \\
& \left.+\sum_{\mathrm{j}=\mathrm{n}+1}^{\mathrm{N}+\mathrm{n}} \overline{\tau_{\mathrm{j}-\mathrm{n}}} \beta_{\mathrm{j}} \frac{1-\mathrm{i}}{\sqrt{2} \varepsilon_{\mathrm{j}-\mathrm{n}}}-\frac{1}{2}\right) \\
& +\tau_{\mathrm{n}}-\theta_{\mathrm{n}}-\frac{1}{2} \tau_{0} \beta_{\mathrm{n}}=0
\end{aligned}
$$

More details are given in appendix A.

Consequently, the computation of $\tau_{\mathrm{n}}$ from Eq. (10) completely determines the temperature field. However, this determination requires knowledge of $\theta_{\mathrm{n}}$ and $\beta_{\mathrm{n}}$, which can be derived from the Fourier Series properties ( $2 \pi$ periodicity) of $\theta(\varphi)$ and $\beta(\varphi)$.

$\theta(\varphi)=\sum_{n=-N}^{N} \theta_{n} e^{i n \varphi}$

where:

$$
\left\{\begin{array}{l}
\theta_{0}=\frac{1}{2 \pi}\left(\theta_{1} \varphi_{1}+\theta_{2}\left(2 \pi-\varphi_{1}\right)\right) \\
\theta_{\mathrm{n}}=\frac{1}{2 \pi \mathrm{n}}\left(\theta_{1}-\theta_{2}\right)\left(\mathrm{e}^{-i n \varphi_{1}}-1\right) \mathrm{i}
\end{array}\right.
$$

in the case where one type of cooling condition is applied:

$\beta(\varphi)=\sum_{\mathrm{n}=-\mathrm{N}}^{\mathrm{N}} \beta_{\mathrm{n}} \mathrm{e}^{i n \varphi}$

where:

$\left\{\begin{array}{l}\beta_{0}=\frac{\lambda}{2 \pi R h}\left(2 \pi-\varphi_{1}\right) \\ \beta_{\mathrm{n}}=\frac{\lambda}{2 \pi R h n} \mathrm{i}\left(1-\mathrm{e}^{-i n \varphi_{1}}\right)\end{array}\right.$

in the case where two kinds of cooling are applied, the angle $\varphi_{2}$ is introduced, Figure 2.

Hence, some changes need to be introduced in the formulation of $\beta_{\mathrm{n}}$.

$$
\left\{\begin{aligned}
\beta_{0}= & \frac{1}{2 \pi R}\left(\frac{\lambda}{h_{1}}\left(\varphi_{2}-\varphi_{1}\right)+\frac{\lambda}{h_{2}}\left(2 \pi-\varphi_{2}\right)\right) \\
\beta_{\mathrm{n}}= & \frac{1}{2 \pi R n}\left(\frac{\lambda}{h_{1}}\left(\mathrm{e}^{-i n \varphi_{2}}-\mathrm{e}^{-i n \varphi_{1}}\right)\right. \\
& \left.+\frac{\lambda}{h_{2}}\left(1-\mathrm{e}^{-i n \varphi_{2}}\right)\right)
\end{aligned}\right.
$$

Finally, the development in Fourier series provides an analytical solution of the temperature field as a function of the radius ratio $\xi$ and the circumferential angle $\varphi$ :

$\left.T(\xi, \varphi)=\tau_{0}+\frac{2}{\sqrt{\xi}} \operatorname{Re} \sum_{\mathrm{n}=1}^{\mathrm{N}} \tau_{\mathrm{n}} \mathrm{e}^{\frac{(1+\mathrm{i})(\xi-1)}{\sqrt{2} \varepsilon_{\mathrm{n}}}+i n \varphi}\right)$

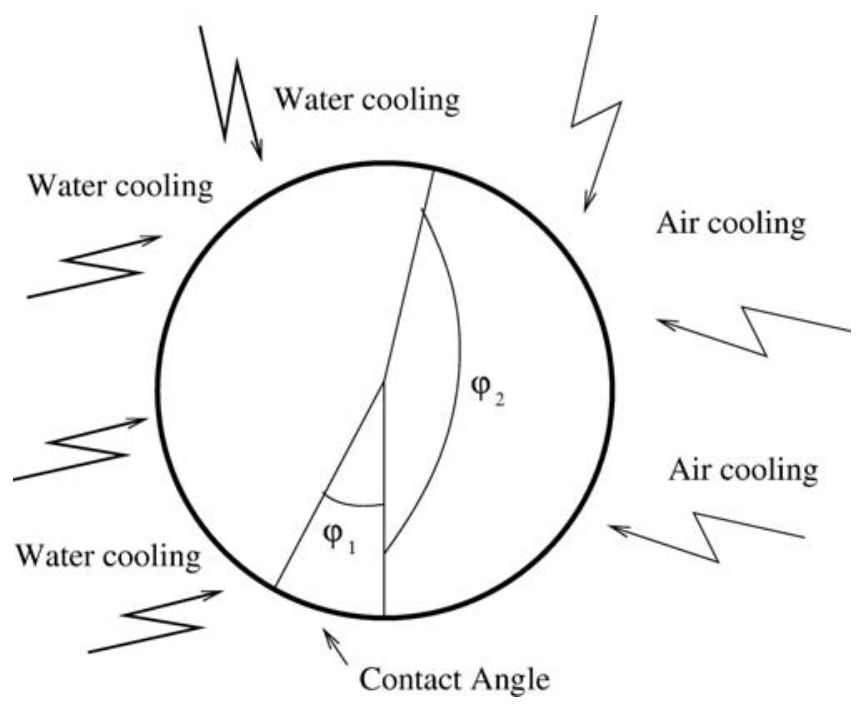

Figure 2. Schematic diagram of the work roll for both kinds of spray cooling (for instance combined air-water cooling) 
Where $\operatorname{Re}(\mathrm{z})$ is the real part of the complex number $\mathrm{z}$.

Following on from this, the thermal gradient distributions can be computed by derivation from the previous equation:

$$
\begin{aligned}
\frac{\partial T}{\partial r}(\xi, \varphi)= & \frac{2}{\operatorname{R} \sqrt{\xi}} \operatorname{Re} \sum_{\mathrm{n}=1}^{\mathrm{N}} \tau_{\mathrm{n}}\left(\frac{1+\mathrm{i}}{\sqrt{2} \varepsilon_{\mathrm{n}}}-\frac{1}{2 \xi}\right) \\
& \left.\times \mathrm{e}^{\frac{(1+\mathrm{i})(\xi-1)}{\sqrt{2} \varepsilon_{\mathrm{n}}}+\mathrm{in} \varphi}\right)
\end{aligned}
$$$$
\left.\frac{\partial T}{\partial \varphi}(\xi, \varphi)=\frac{2}{\sqrt{\xi}} \operatorname{Re} \sum_{\mathrm{n}=1}^{\mathrm{N}} i n \tau_{\mathrm{n}} \mathrm{e}^{\frac{(1+i)(\xi-1)}{\sqrt{2} \varepsilon_{\mathrm{n}}}+i n \varphi}\right)
$$

More developments are given in appendix B.

\section{Numerical implementation}

The objective of the numerical procedure is to compute the temperature field $T$ and its gradient in the hot roll during the hot rolling process. This consists in the computation of $\tau_{\mathrm{i}}, \mathrm{i}=0, \pm 1, \ldots, \pm \mathrm{N}$ from the system of equations described below.

The objective of the numerical implementation is to evaluate Eqs. (7) and (10). The main difficulty is then to calculate the coefficient $\tau_{\mathrm{n}} \forall n=0, \pm 1, \ldots, \pm \mathrm{N}$. For this purpose, Eq. (10) is re-written under a matrix form which leads to the following relation:

$$
\begin{aligned}
n= & 0:\left(\beta_{-\mathrm{N}} \alpha_{\mathrm{N}} \tau_{\mathrm{N}}+\ldots+\beta_{-1} \alpha_{1} \tau_{1}\right) \\
& +\left(\beta_{1} \overline{\alpha_{1}} \overline{\tau_{1}}+\ldots+\beta_{\mathrm{N}} \overline{\alpha_{\mathrm{N}}} \overline{\tau_{\mathrm{N}}}\right)+\tau_{0}-\frac{\tau_{0}}{2} \beta_{0}=\theta_{0} \\
\vdots & \\
\vdots & \\
n= & N:\left(\beta_{0} \alpha_{\mathrm{N}} \tau_{\mathrm{N}}+\ldots+\beta_{\mathrm{N}-1} \alpha_{1} \tau_{1}\right) \\
& +\left(\beta_{\mathrm{N}+1} \overline{\alpha_{1}} \overline{\tau_{1}}+\ldots+\beta_{2 \mathrm{~N}} \overline{\alpha_{\mathrm{N}}} \overline{\tau_{\mathrm{N}}}\right)+\tau_{\mathrm{N}}-\frac{\tau_{0}}{2} \beta_{\mathrm{N}} \\
& =\theta_{\mathrm{N}}
\end{aligned}
$$

with:

$\alpha_{\mathrm{n}}=\frac{1+i}{\sqrt{2} \varepsilon_{\mathrm{n}}}-\frac{1}{2}$
The system could be written in matrix form, such as:

$$
\begin{gathered}
\underbrace{\left(\begin{array}{cccc}
-\frac{\beta_{0}}{2} & \alpha_{1} \beta_{-1} & \ldots & \alpha_{\mathrm{N}} \beta_{-\mathrm{N}} \\
\vdots & \vdots & \ddots & \vdots \\
-\frac{\beta_{\mathrm{N}}}{2} & \alpha_{1} \beta_{\mathrm{N}-1} & \ldots & \alpha_{\mathrm{N}} \beta_{0}
\end{array}\right)}_{\mathrm{A}}\left(\begin{array}{c}
\tau_{0} \\
\vdots \\
\tau_{\mathrm{N}}
\end{array}\right) \\
+\underbrace{\left(\begin{array}{ccc}
\overline{\alpha_{1}} \beta_{1} & \ldots & \overline{\alpha_{\mathrm{N}}} \beta_{\mathrm{N}} \\
\vdots & \ddots & \vdots \\
\overline{\alpha_{1}} \beta_{\mathrm{N}+1} & \ldots & \overline{\alpha_{\mathrm{N}}} \beta_{2 \mathrm{~N}}
\end{array}\right)}_{\mathrm{B}} \underbrace{\left(\begin{array}{c}
\overline{\tau_{1}} \\
\vdots \\
\overline{\tau_{\mathrm{N}}}
\end{array}\right)}_{\bar{\tau}}
\end{gathered}
$$

$$
+\left(\begin{array}{c}
\tau_{0} \\
\vdots \\
\tau_{\mathrm{N}}
\end{array}\right)=\left(\begin{array}{c}
\theta_{0} \\
\vdots \\
\theta_{\mathrm{N}}
\end{array}\right)
$$

where:

$$
\begin{aligned}
& A \in \mathcal{M}_{\mathrm{N}+1, \mathrm{~N}+1}(\mathbb{C}) ; \quad B \in \mathcal{M}_{\mathrm{N}+1, \mathrm{~N}}(\mathbb{C}) \\
& \tau, \bar{\tau} \in \mathbb{C}^{\mathrm{N}} ; \quad \theta=\left(\begin{array}{c}
\theta_{1} \\
\vdots \\
\theta_{\mathrm{N}}
\end{array}\right) \in \mathbb{C}^{\mathrm{N}}
\end{aligned}
$$

We note:

$$
\begin{aligned}
& \tilde{\theta}=\left(\begin{array}{c}
\theta_{0} \\
\theta
\end{array}\right) \in \mathbb{C}^{\mathrm{N}+1} ; \quad \tilde{\tau}=\left(\begin{array}{c}
\tau_{0} \\
\tau
\end{array}\right) \in \mathbb{C}^{\mathrm{N}+1} ; \\
& \tilde{\bar{\tau}}=\left(\begin{array}{c}
\tau_{0} \\
\bar{\tau}
\end{array}\right) \in \mathbb{C}^{\mathrm{N}+1} ; \\
& \tilde{B}=\left(\begin{array}{cc}
0 & \\
\vdots & B \\
0 &
\end{array}\right) \in \mathcal{M}_{\mathrm{N}+1, \mathrm{~N}+1}(\mathbb{C})
\end{aligned}
$$

Knowing that $\tilde{B} \tilde{\tau}=B \bar{\tau}$, the following linear system is obtained:

$$
\left(A+I_{\mathrm{N}+1}\right) \tilde{\tau}+\tilde{\mathrm{B}} \overline{\tilde{\tau}}=\tilde{\theta}
$$


where

$$
\left\{\begin{array}{l}
A=\operatorname{Re}(A)+\mathrm{i} \operatorname{Im}(A) \\
\tilde{B}=\operatorname{Re}(\tilde{B})+\mathrm{i} \operatorname{Im}(\tilde{B}) \\
\tilde{\tau}=a+i b ; a, b \in \mathbb{R}^{\mathrm{N}+1}
\end{array}\right.
$$

and

$$
a=\left(\begin{array}{c}
a_{0} \\
\vdots \\
a_{\mathrm{N}}
\end{array}\right) ; \quad b=\left(\begin{array}{c}
b_{0} \\
\vdots \\
b_{\mathrm{N}}
\end{array}\right)
$$

In the previous system, $\operatorname{Re}(A)$ (respectively $\operatorname{Im}(A))$ is the real part of the complex number $A$ (respectively the imaginary part).

Equaling real and imaginary parts of the Eq. (12), it follows:

$\left(\operatorname{Re}(A)+\operatorname{Re}(\tilde{B})+I_{\mathrm{N}+1}\right) \mathrm{a}+(\operatorname{Im}(\tilde{B})-\operatorname{Im}(A)) b$ $=\operatorname{Re}(\tilde{\theta})$

$(\operatorname{Im}(A)+\operatorname{Im}(\tilde{B})) a+\left(\operatorname{Re}(A)-\operatorname{Re}(\tilde{B})+I_{\mathrm{N}+1}\right) b$ $=\operatorname{Im}(\tilde{\theta})$

and we note:

$$
\left\{\begin{array}{l}
C_{1}=\operatorname{Re}(A)+\operatorname{Re}(\tilde{B})+I_{\mathrm{N}+1} \\
C_{2}=\operatorname{Im}(\tilde{B})-\operatorname{Im}(A) \\
C_{3}=\operatorname{Im}(A)+\operatorname{Im}(\tilde{B}) \\
C_{4}=\operatorname{Re}(A)-\operatorname{Re}(\tilde{B})+I_{\mathrm{N}+1}
\end{array}\right.
$$

It results that the real and imaginary parts of $\tau$ can be obtained from the linear system:

$$
\left(\begin{array}{l}
\mathrm{a} \\
b
\end{array}\right)=\left(\begin{array}{ll}
\mathrm{C}_{1} & \mathrm{C}_{2} \\
\mathrm{C}_{3} & C_{4}
\end{array}\right)^{-1}\left(\begin{array}{l}
\operatorname{Re}(\tilde{\theta}) \\
\operatorname{Im}(\tilde{\theta})
\end{array}\right)
$$

Finally, an explicit formulation of the coefficient $A_{\mathrm{kj}}$ (respectively $\tilde{B}_{\mathrm{kj}}$ ) of the matrix $A$ (respectively of matrix $\tilde{B}$ ) completes the numerical implementation.

From Eq. (12), we can write:

$$
(A \tilde{\tau}+\tilde{\tau}+\tilde{B} \overline{\tilde{\tau}})_{\mathrm{k}}=\tilde{\theta}_{\mathrm{k}} \quad \forall k=1, \ldots, N+1
$$

or under index form:

$$
\sum_{\mathrm{j}=1}^{\mathrm{N}+1}\left(\tilde{A}_{\mathrm{kj}} \tilde{\tau}_{\mathrm{j}}+\tilde{B}_{\mathrm{kj}} \bar{\tau}_{\mathrm{j}}\right)+\tilde{\tau}_{\mathrm{k}}=\tilde{\theta}_{\mathrm{k}} \quad \forall \mathrm{k}=1, \ldots, N+1
$$

with:

$A_{\mathrm{kj}}= \begin{cases}-\frac{\beta_{\mathrm{k}-1}}{2} ; & \forall k=1, \ldots, N+1 ; \quad \mathrm{j}=1 \\ \alpha_{\mathrm{j}-1} \beta_{\mathrm{k}-\mathrm{j}} ; & \forall(k, \mathrm{j})=1, \ldots, N+1 ; \quad \mathrm{j} \neq 1\end{cases}$

$\tilde{\mathrm{B}}_{\mathrm{kj}}=\left\{\begin{array}{l}0 ; \quad \forall k=1, \ldots, \mathrm{N}+1 ; \quad \mathrm{j}=1 \\ \overline{\alpha_{\mathrm{j}-1}} \beta_{\mathrm{k}+\mathrm{j}-2} ; \quad \forall(k, \mathrm{j})=1, \ldots, \mathrm{N}+1 ; \\ \mathrm{j} \neq 1\end{array}\right.$

The different steps leading to the temperature field formulation are illustrated, Figure 3.

\section{Results}

Based on the previous numerical procedure, a program was developed under MATLAB software to solve the distribution of the temperature in the roll. This methodology can be applied to investigate the influence of several process parameters, like the strip temperature and the kinds of cooling employed. The thermo-physical properties of the roll material and the process parameters are given, Table 1.

Table 1. Process and physical properties

\begin{tabular}{ll}
\hline$\varphi_{1}=12 \pi / 180$ & Contact arc length $[\mathrm{rad}]$ \\
$R=0.35$ & Roll body radius $[\mathrm{m}]$ \\
$\omega=0.3$ & Angular velocity of rotation of the roll $[\mathrm{rad} / \mathrm{s}]$ \\
$C_{\mathrm{p}}=510$ & Heat capacity $[\mathrm{J} / \mathrm{kg} / \mathrm{K}]$ \\
$\rho=7800$ & Density $\left[\mathrm{kg} / \mathrm{m}^{3}\right]$ \\
$\lambda=16$ & Thermal conductivity $[\mathrm{W} / \mathrm{m} / \mathrm{K}]$ \\
$\theta_{1}=885(552)$ & Strip temperature $\left[\mathrm{K}\left({ }^{\circ} \mathrm{C}\right)\right]$ \\
$\theta_{2}=293(25)$ & Air or water temperature $\left[\mathrm{K}\left({ }^{\circ} \mathrm{C}\right)\right]$ \\
$h=1500$ & Forced air cooling thermal exchange coefficient $\left[\mathrm{W} / \mathrm{m}^{2} / \mathrm{K}\right]$ \\
$h=36300$ & Forced water cooling thermal exchange coefficient $\left[\mathrm{W} / \mathrm{m}^{2} / \mathrm{K}\right]$ \\
\hline
\end{tabular}




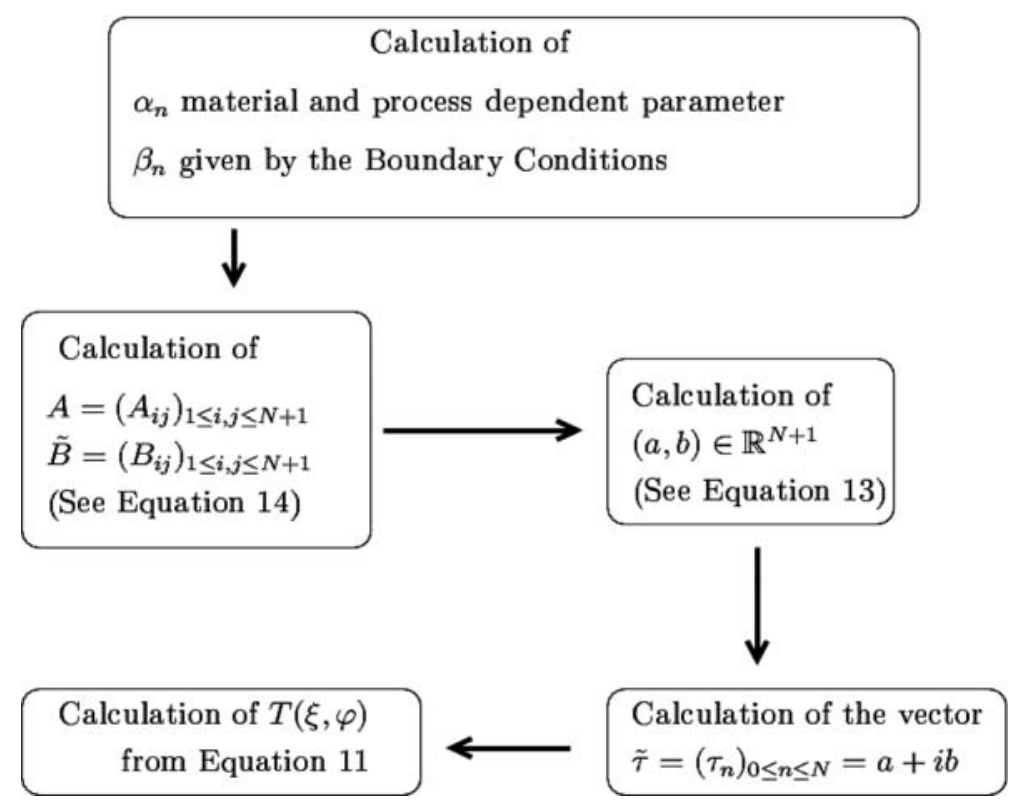

Figure 3. Calculation stages of the temperature field

\subsection{Number of terms in Fourier series}

The first analysis is related to the number of terms $\mathrm{N}$ considered in the Fourier series in order to obtain relevant results. A minimal number of terms of 3000 is required in order to reproduce the boundary conditions on the arc length in contact with the strip. The model response for different values of the parameter $N$ is compared, Figure 4. A mean temperature of $824 \mathrm{~K}\left(551^{\circ} \mathrm{C}\right)$ is found close to those considered in the Dirichlet boundary condition intended to reproduce the strip temperature $\left(\mathrm{T}=825 \mathrm{~K}\left(552{ }^{\circ} \mathrm{C}\right)\right)$.

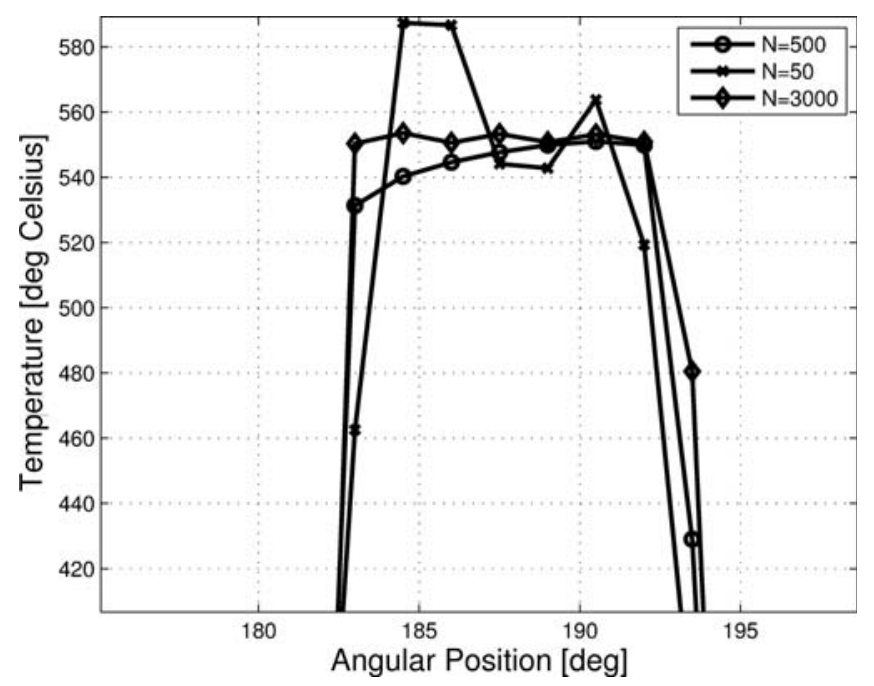

Figure 4. Influence of the number of terms in the Fourier series on the trend of the temperature fields along the thermal contact
However, smaller values are not suitable, because they induce an important drop in the temperature along the arc length, Figure 4.

All the results presented below are computed using $N=3000$.

Different boundary conditions were applied and predictions of temperature profiles were examined in comparison with results using the Finite Element Method and measurements from [9, 28].

The evolution of the temperature versus the rolling angle for different thicknesses is shown, Fig-

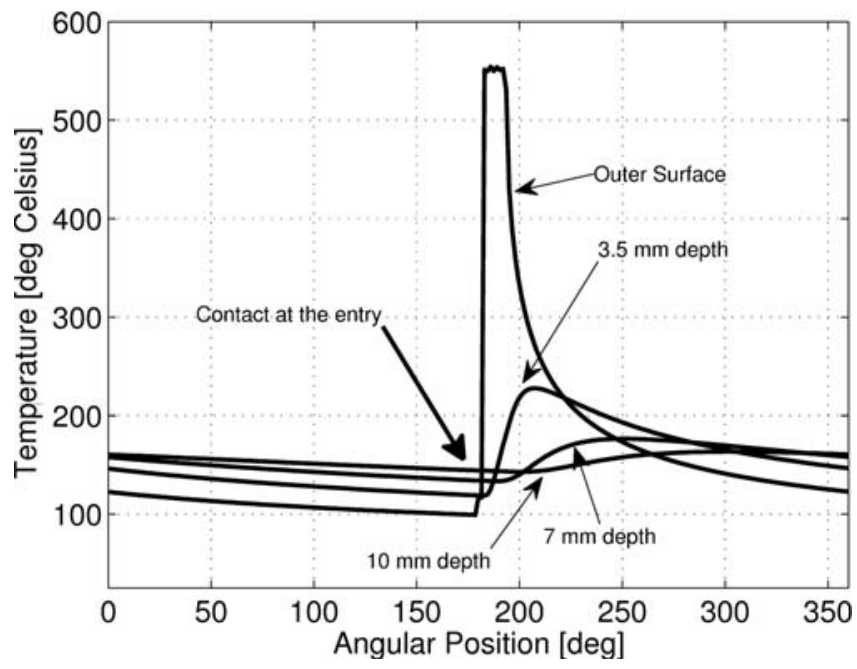

Figure 5. Temperature evolution for air spray cooling at different depth locations 
ure 5. As can be seen, the temperature at the roll surface reaches $818 \mathrm{~K}\left(545^{\circ} \mathrm{C}\right)$ along the contact arc of $12^{\circ}$. Afterwards, the temperature decreases rapidly with the rolling angle. However, a little further from the surface (10 $\mathrm{mm}$ in depth), the temperature barely reaches $473 \mathrm{~K}\left(200^{\circ} \mathrm{C}\right)$. From this depth to the roll center, the temperature does not evolve any more. The obtained temperature profiles confirm the very localized heated zone on the roll and are in agreement with results obtained using the finite element method and available measurements [13, 19, 28]. However, the maximum temperature at the roll surface in the contact arc depends on the roll speed (contact time), the coefficient of heat transfer, the roll diameter (contact angle) and the thermo-physical properties of the roll material.

A comparison of the temperature evolution for three different spray cooling conditions was plotted (air or water spray cooling and a combined airwater cooling), Figure 6 . For the water spray cooling, the model prediction shows a rapid decrease in the temperature from $833 \mathrm{~K}\left(560^{\circ} \mathrm{C}\right)$ down to $298 \mathrm{~K}$ $\left(25^{\circ} \mathrm{C}\right.$ ), whereas a higher value (around $373 \mathrm{~K}$ $\left.\left(100^{\circ} \mathrm{C}\right)\right)$ was found in the case of air cooling.

The third case is a combination of air and water spray cooling. First, the air spray cooling is applied followed by the water spray cooling. The separation angle is equal to $\varphi_{2}=90^{\circ}$ Figure 6 .

The temperature distribution obtained at the roll surface is quite close to the curve obtained with air spray cooling for the first part $\varphi_{2}=90^{\circ}$ ) and presents a similar profile to the temperature distribution

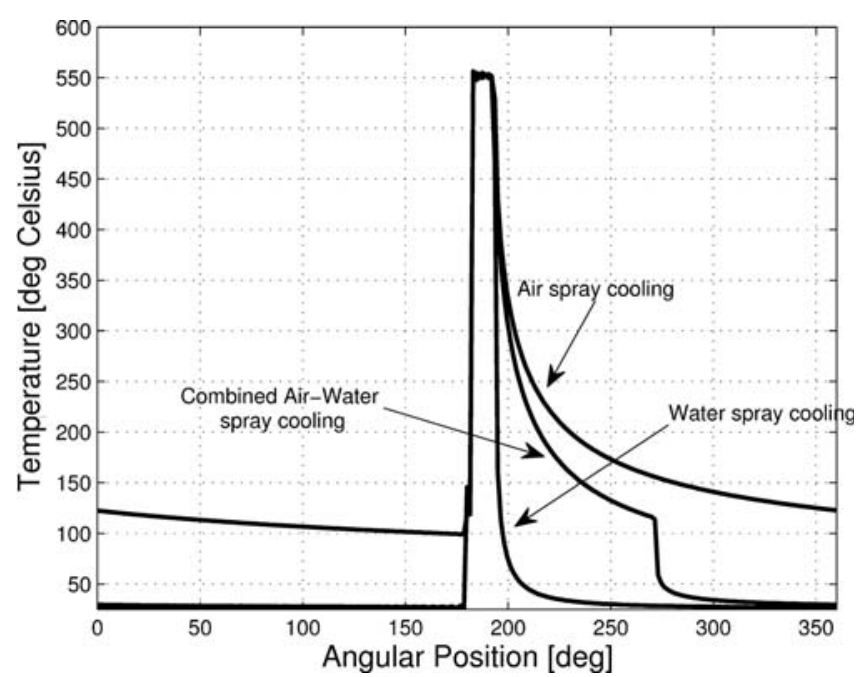

Figure 6. Comparison of the temperature evolution for air or water spray cooling and for a combined air-water spray cooling in the water spray cooling case in the second part $\left(90^{\circ}<\varphi_{2}<360^{\circ}\right)$.

However, an offset of the curve is observed in the transition zone (air to water spray cooling).

\subsection{Effects of process parameters on the temperature distribution}

The distribution of the temperature in the roll depends on the process parameters, such as the roll pressure and roll diameter, both of which affect the contact arc, and is also dependent on the roll speed which determines the contact time and hence has an effect on the heat exchange conditions.

In the proposed modelling the temperature distribution is directly expressed as a function of the process parameters (contact angle, angles where the spray cooling is applied and roll speed). In this model the strip is only represented by the contact arc and heat exchange coefficient. The impact of roll pressure can be then appreciated through the contact angle.

To examine the influence of the contact angle and the roll speed on the maximum temperature and the heat flux on the roll surface, simulations were conducted by varying their values. Results are presented, Table 2. These results indicate that the increase in the contact angle increases the heat transfer between the strip and the roll. Furthermore, it is shown that a low roll speed favors the heat exchange from the strip to the roll, Figure 7 . These results are consistent and supported by the general observations in the literature.

\subsection{Impact of the contact conditions}

The contact between the strip and the roll is not perfect in general. This is due to the existence of a thermal resistance $R_{\mathrm{c}}$ which limits the heat transfer. In the previous results, the contact between the strip and the roll was assumed as a perfect contact, and was modelled as a Dirichlet condition. The new

Table 2. Influence of the contact arc length on the mean temperature and on the thermal flux undergone by the roll

\begin{tabular}{lll}
\hline $\begin{array}{l}\text { Contact angle } \\
{\left[{ }^{\circ}\right]}\end{array}$ & $\begin{array}{l}T_{\text {mean }} \\
{\left[\mathrm{K}\left({ }^{\circ} \mathrm{C}\right)\right]}\end{array}$ & $\begin{array}{l}\text { Thermal flux } \\
{\left[\mathrm{W} / \mathrm{m}^{2}\right]}\end{array}$ \\
\hline 5 & $807.5(534.4)$ & $3.3 \times 10^{5}$ \\
\hline 11.7 & $818(545)$ & $4.71 \times 10^{5}$ \\
\hline 20 & $821(548)$ & $5.69 \times 10^{5}$ \\
\hline
\end{tabular}




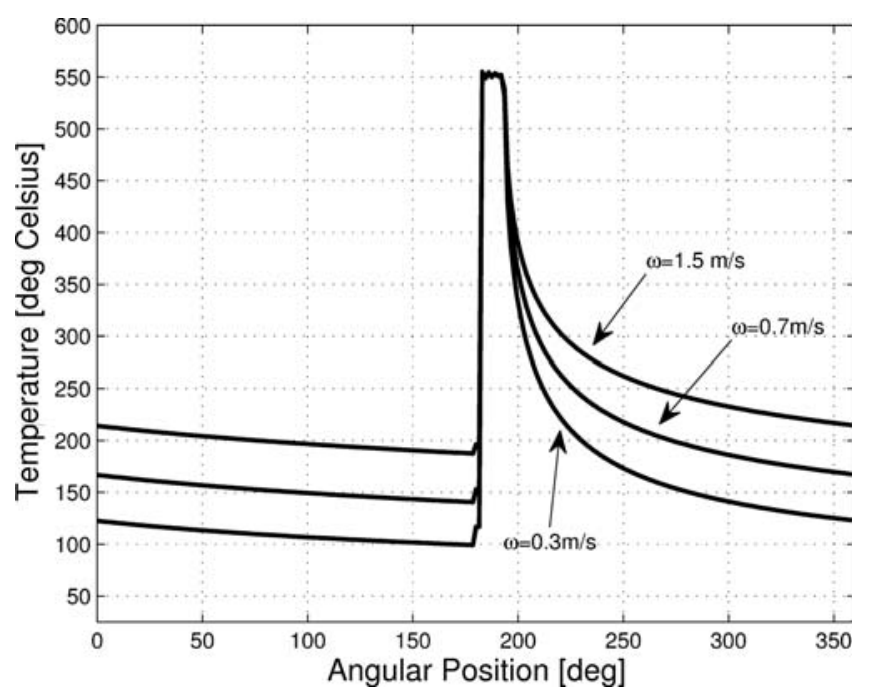

Figure 7. Influence of the angular velocity on the temperature distribution within the roll

boundary condition requires some changes in the model formulation by replacing Dirichlet with Neumann boundary conditions. The development of these changes is reported in Appendix C.

The temperature distribution from the roll surface is plotted for three thicknesses, Figure 8. The curves obtained have the same trends as the previous ones but the maximum temperature along the arc length is lower $\left(\mathrm{T}=791 \mathrm{~K}\left(518^{\circ} \mathrm{C}\right)\right)$. Furthermore, it can be noted that the peak temperature has shifted towards the rotation direction in accordance with the depth [29]. This is essentially due to convection caused by the rotation of the roll.

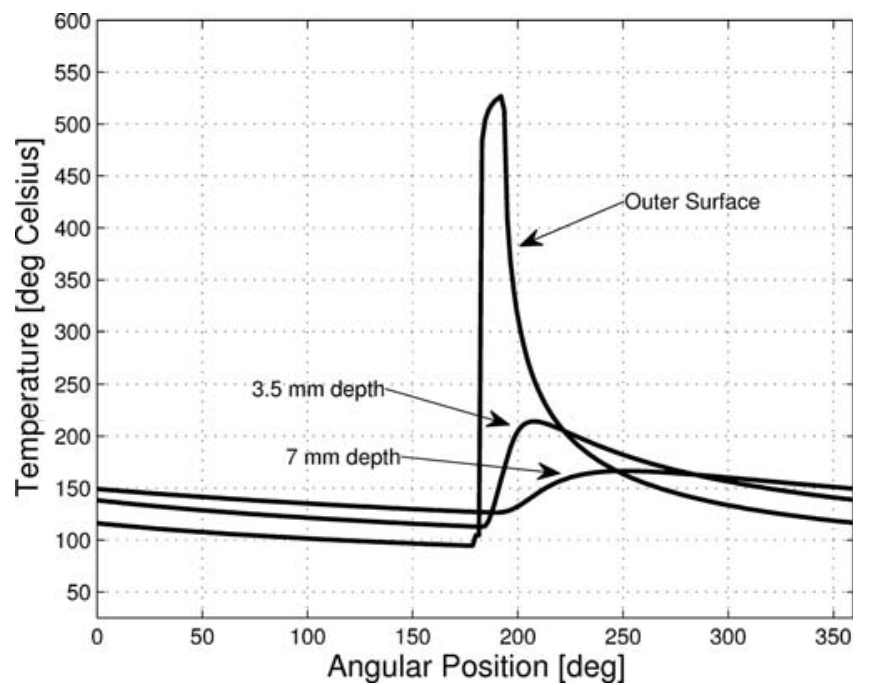

Figure 8. Temperature evolution for different thicknesses within the roll in the case of a thermal contact resistance $R_{\mathrm{c}}=$ $10^{-5} \mathrm{~K} \cdot \mathrm{m}^{2} \mathrm{~W}^{-1}$

\section{Conclusion}

In this work, an analytical methodology was developed in order to assess the temperature field of work rolls during the hot rolling process. The model gives relevant results to predict the very high thermal gradient occurring at the surface of the roll body. This approach seems to be more suitable than a standard finite element calculation, which requires a very thin mesh close to the surface of the roll and consequently will require more time-consuming calculations without ensuring good reliability. The present model considers a stationary thermal behaviour and does not take into account the transient phenomena. It allows several process parameters to be investigated, such as the arc length in contact with the strip, the angular velocity of rotation, or the cooling and heating conditions. Moreover, the number of terms considered in the Fourier series have to be carefully calibrated $(N>2000)$ in order to reproduce the boundary condition along the thermal contact. From this investigation, future work will seek to evaluate the stress levels within the rolls generated by the thermal gradient.

\section{Appendix A}

It is obvious that Eqs. (7) and (9) lead to the following form:

$$
\begin{aligned}
& \left.\sum_{\mathrm{j}=-\mathrm{N}+\mathrm{n}}^{\mathrm{N}+\mathrm{n}} \tau_{\mathrm{n}-\mathrm{j}} \beta_{\mathrm{j}} \frac{1+\mathrm{i}}{\sqrt{2} \varepsilon_{\mathrm{n}-\mathrm{j}}}-\frac{1}{2}\right)+\tau_{\mathrm{n}}-\theta_{\mathrm{n}}=0 \\
& \forall n=0, \pm 1, \ldots, \pm \mathrm{N}
\end{aligned}
$$

Moreover, the Fourier series properties give $T_{-\mathrm{n}}=\overline{T_{\mathrm{n}}}$ and then $\tau_{-\mathrm{n}}=\overline{\tau_{\mathrm{n}}}$.

Hence, the previous equation can be re-written as:

$$
\begin{aligned}
-\frac{1}{2} \tau_{0} \beta_{\mathrm{n}}+ & \left.\sum_{\mathrm{j}=-\mathrm{N}+\mathrm{n}}^{\mathrm{n}-1}+\sum_{\mathrm{j}=\mathrm{n}+1}^{\mathrm{N}+\mathrm{n}}\right) \\
& \left.\left.\times \tau_{\mathrm{n}-\mathrm{j}} \beta_{\mathrm{j}} \frac{1+\mathrm{i}}{\sqrt{2} \varepsilon_{\mathrm{n}-\mathrm{j}}}-\frac{1}{2}\right)\right) \\
+ & \tau_{\mathrm{n}}-\theta_{\mathrm{n}}=0
\end{aligned}
$$

$\forall n=0, \pm 1, \ldots, \pm \mathrm{N}$ 
where:

$$
\begin{aligned}
& \left.\sum_{j=n+1}^{N+n} \tau_{n-j} \beta_{j} \frac{1+i}{\sqrt{2} \varepsilon_{n-j}}-\frac{1}{2}\right) \\
& \left.=\sum_{j=n+1}^{N+n} \overline{\tau_{j-n}} \beta_{j} \frac{1+i}{i \sqrt{2} \varepsilon_{j-n}}-\frac{1}{2}\right) \\
& \left.=\sum_{j=n+1}^{N+n} \overline{\tau_{j-n}} \beta_{j} \frac{1-i}{\sqrt{2} \varepsilon_{j-n}}-\frac{1}{2}\right)
\end{aligned}
$$

Finally:

$\left.\left.-\frac{1}{2} \tau_{0} \beta_{n}+\sum_{j=-N+n}^{n-1} \tau_{n-j} \beta_{j} \frac{1+i}{\sqrt{2} \varepsilon_{n-j}}-\frac{1}{2}\right)\right)$

$\left.\left.+\sum_{\mathrm{j}=\mathrm{n}+1}^{\mathrm{N}+\mathrm{n}} \overline{\tau_{\mathrm{j}-\mathrm{n}}} \beta_{\mathrm{j}} \frac{1-\mathrm{i}}{\sqrt{2} \varepsilon_{\mathrm{j}-\mathrm{n}}}-\frac{1}{2}\right)\right)+\tau_{\mathrm{n}}-\theta_{\mathrm{n}}=0$

$\forall n=0, \pm 1, \ldots, \pm \mathrm{N}$

If only $\mathrm{n}=-N, \ldots,-1,0$ are considered, the following form is deduced:

$\overline{\left.\left.-\frac{1}{2} \tau_{0} \beta_{\mathrm{n}}+\sum_{\mathrm{j}=-\mathrm{N}+\mathrm{n}}^{\mathrm{n}-1} \tau_{\mathrm{n}-\mathrm{j}} \beta_{\mathrm{j}} \frac{1+\mathrm{i}}{\sqrt{2} \varepsilon_{\mathrm{n}-\mathrm{j}}}-\frac{1}{2}\right)\right)}$

$+\overline{\left.\left.\sum_{\mathrm{j}=\mathrm{n}+1}^{\mathrm{N}+\mathrm{n}} \overline{\tau_{\mathrm{j}-\mathrm{n}}} \beta_{\mathrm{j}} \frac{1-\mathrm{i}}{\sqrt{2} \varepsilon_{\mathrm{j}-\mathrm{n}}}-\frac{1}{2}\right)\right)+\tau_{\mathrm{n}}-\theta_{\mathrm{n}}}=0$

IE:

$\left.\left.-\frac{1}{2} \tau_{0} \beta_{-n}+\sum_{j=-N+n}^{n-1} \tau_{j-n} \beta_{-j} \frac{1-i}{\sqrt{2} \varepsilon_{n-j}}-\frac{1}{2}\right)\right)$

$\left.\left.+\sum_{\mathrm{j}=\mathrm{n}+1}^{\mathrm{N}+\mathrm{n}} \tau_{\mathrm{j}-\mathrm{n}} \beta_{-\mathrm{j}} \frac{1+\mathrm{i}}{\sqrt{2} \varepsilon_{\mathrm{j}-\mathrm{n}}}-\frac{1}{2}\right)\right)+\tau_{-\mathrm{n}}-\theta_{-\mathrm{n}}=0$
A change index leads to:

$$
\begin{aligned}
& \left.\left.-\frac{1}{2} \tau_{0} \beta_{-n}+\sum_{j=-n+1}^{N-n} \tau_{-j-n} \beta_{j} \frac{1-i}{\sqrt{2} \varepsilon_{n+j}}-\frac{1}{2}\right)\right) \\
& \left.\left.+\sum_{j=-N-n}^{-n-1} \tau_{-j-n} \beta_{j} \frac{1+i}{\sqrt{2} \varepsilon_{-j-n}}-\frac{1}{2}\right)\right) \\
& +\tau_{-n}-\theta_{-n}=0
\end{aligned}
$$

Now, assuming $m=-n, m=0, \ldots, N$, have to be considered:

$$
\begin{aligned}
& \left.\left.-\frac{1}{2} \tau_{0} \beta_{\mathrm{m}}+\sum_{\mathrm{j}=\mathrm{m}+1}^{\mathrm{N}+\mathrm{m}} \tau_{-\mathrm{j}+\mathrm{m}} \beta_{\mathrm{j}} \frac{1-\mathrm{i}}{\sqrt{2} \varepsilon_{-\mathrm{m}+\mathrm{j}}}-\frac{1}{2}\right)\right) \\
& \left.\left.+\sum_{\mathrm{j}=-\mathrm{N}+\mathrm{m}}^{\mathrm{m}-1} \tau_{-\mathrm{j}+\mathrm{m}} \beta_{\mathrm{j}} \frac{1+\mathrm{i}}{\sqrt{2} \varepsilon_{-\mathrm{j}+\mathrm{m}}}-\frac{1}{2}\right)\right) \\
& +\tau_{\mathrm{m}}-\theta_{\mathrm{m}}=0
\end{aligned}
$$

And the final formulation is found:

$$
\left.\left.\sum_{j=n+1}^{N+n} \tau_{-j+n} \beta_{j} \frac{1-i}{\sqrt{2} \varepsilon_{-n+j}}-\frac{1}{2}\right)\right)
$$

$$
\begin{aligned}
& \left.\left.+\sum_{\mathrm{j}=-\mathrm{N}+\mathrm{n}}^{\mathrm{n}-1} \tau_{-\mathrm{j}+\mathrm{n}} \beta_{\mathrm{j}} \frac{1+\mathrm{i}}{\sqrt{2} \varepsilon_{-\mathrm{j}+\mathrm{n}}}-\frac{1}{2}\right)\right) \\
& +\tau_{\mathrm{n}}-\theta_{\mathrm{n}}-\frac{1}{2} \tau_{0} \beta_{\mathrm{n}}=0
\end{aligned}
$$

\section{Appendix B}

First, we know that: $T_{\mathrm{n}}(\xi)=\tau_{\mathrm{n}} \frac{1}{\sqrt{\xi}} \mathrm{e}^{\frac{(1+\mathrm{i})(\xi-1)}{\sqrt{2} \varepsilon_{\mathrm{n}}}}$ close to the surface of the roll $(\xi=1)$. Note that for $n=0$, a constant function provides a solution of the next differential equation:

$$
T_{0}^{\prime \prime}(\xi)+\frac{1}{\xi} T_{0}^{\prime}(\xi)=0 \quad \forall \xi \in[0 ; 1]
$$


Thus:

$$
T_{0}(\xi)=T_{0}(\xi=1)=\tau_{0}
$$

Calculation of $T(\xi, \varphi)$ :

$$
\begin{aligned}
T(\xi, \varphi) & =\sum_{\mathrm{n}=-\mathrm{N}}^{\mathrm{N}} T_{\mathrm{n}}(\xi) \mathrm{e}^{i n \varphi} \\
& \left.=T_{0}(\xi)+\sum_{\mathrm{n}=-\mathrm{N}}^{-1}+\sum_{\mathrm{n}=1}^{\mathrm{N}}\right) T_{\mathrm{n}}(\xi) \mathrm{e}^{i n \varphi}
\end{aligned}
$$

which implies:

$\left.T(\xi, \varphi)=\tau_{0}+\sum_{\mathrm{n}=-\mathrm{N}}^{-1}+\sum_{\mathrm{n}=1}^{\mathrm{N}}\right) \frac{\tau_{\mathrm{n}}}{\sqrt{\xi}} \mathrm{e}^{\frac{(1+\mathrm{i})(\xi-1)}{\sqrt{2} \varepsilon_{\mathrm{n}}}} \mathrm{e}^{i n \varphi}$

Then:

$$
\begin{aligned}
\sum_{\mathrm{n}=-\mathrm{N}}^{-1} \frac{\tau_{\mathrm{n}}}{\sqrt{\xi}} \mathrm{e}^{\frac{(1+\mathrm{i})(\xi-1)}{\sqrt{2} \varepsilon_{\mathrm{n}}}} \mathrm{e}^{i n \varphi} & =\sum_{\mathrm{n}=1}^{\mathrm{N}} \frac{\overline{\tau_{\mathrm{n}}}}{\sqrt{\xi}} \mathrm{e}^{\frac{(1-\mathrm{i})(\xi-1)}{\sqrt{2} \varepsilon_{\mathrm{n}}}} \mathrm{e}^{-i n \varphi} \\
& =\sum_{\mathrm{n}=1}^{\mathrm{N}} \frac{\tau_{\mathrm{n}}}{\sqrt{\xi}} \mathrm{e}^{\frac{(1+\mathrm{i})(\xi-1)}{\sqrt{2} \varepsilon_{\mathrm{n}}}} \mathrm{e}^{i n \varphi}
\end{aligned}
$$

Finally:

$$
\begin{aligned}
T(\xi, \varphi)=\tau_{0} & +\sum_{\mathrm{n}=1}^{\mathrm{N}} \frac{\tau_{\mathrm{n}}}{\sqrt{\xi}} \mathrm{e}^{\frac{(1+\mathrm{i})(\xi-1)}{\sqrt{2} \varepsilon_{\mathrm{n}}}} \mathrm{e}^{i n \varphi} \\
& +\sum_{\mathrm{n}=1}^{\mathrm{N}} \frac{\tau_{\mathrm{n}}}{\sqrt{\xi}} \mathrm{e}^{\frac{(1+\mathrm{i})(\xi-1)}{\sqrt{2} \varepsilon_{\mathrm{n}}}} \mathrm{e}^{i n \varphi}
\end{aligned}
$$

and:

$$
T(\xi, \varphi)=\tau_{0}+\frac{2}{\sqrt{\xi}} \operatorname{Re} \sum_{\mathrm{n}=1}^{\mathrm{N}}\left(\tau_{\mathrm{n}} \mathrm{e}^{\frac{(1+\mathrm{i})(\xi-1)}{\sqrt{2} \varepsilon_{\mathrm{n}}}+i n \varphi}\right)
$$

Calculation of $\frac{\partial T}{\partial r}(\xi, \varphi)$ :
This form is provided by a derivation of the temperature formulation.

$$
\begin{aligned}
& \frac{\partial T}{\partial r}(\xi, \varphi)=\frac{1}{R} \frac{\partial T}{\partial \xi}(\xi, \varphi) \\
& \left.=\frac{1}{R} \sum_{\mathrm{n}=-\mathrm{N}}^{-1}+\sum_{\mathrm{n}=1}^{\mathrm{N}}\right) \frac{\tau_{\mathrm{n}}}{\sqrt{\xi}}\left(\frac{1+\mathrm{i}}{\sqrt{2} \varepsilon_{\mathrm{n}}}-\frac{1}{2 \xi}\right) \mathrm{e}^{\frac{(1+\mathrm{i})(\xi-1)}{\sqrt{2} \varepsilon_{\mathrm{n}}}+i n \varphi} \\
& =\frac{1}{R \sqrt{\xi}} \sum_{\mathrm{n}=1}^{\mathrm{N}} \tau_{\mathrm{n}}\left(\frac{1+\mathrm{i}}{\sqrt{2} \varepsilon_{\mathrm{n}}}-\frac{1}{2 \xi}\right) \mathrm{e}^{\frac{(1+\mathrm{i})(\xi-1)}{\sqrt{2} \varepsilon_{\mathrm{n}}}+i n \varphi} \\
& \left.+\sum_{\mathrm{n}=1}^{\mathrm{N}} \overline{\tau_{\mathrm{n}}}\left(\frac{1-\mathrm{i}}{\sqrt{2} \varepsilon_{\mathrm{n}}}-\frac{1}{2 \xi}\right) \mathrm{e}^{\frac{(1-\mathrm{i})(\xi-1)}{\sqrt{2} \varepsilon_{\mathrm{n}}}-i n \varphi}\right) \\
& =\frac{1}{R \sqrt{\xi}} \sum_{\mathrm{n}=1}^{\mathrm{N}} \tau_{\mathrm{n}}\left(\frac{1+\mathrm{i}}{\sqrt{2} \varepsilon_{\mathrm{n}}}-\frac{1}{2 \xi}\right) \mathrm{e}^{\frac{(1+\mathrm{i})(\xi-1)}{\sqrt{2} \varepsilon_{\mathrm{n}}}+i n \varphi}
\end{aligned}
$$

$$
\begin{aligned}
& \left.+\sum_{\mathrm{n}=1}^{\mathrm{N}} \tau_{\mathrm{n}}\left(\frac{1+\mathrm{i}}{\sqrt{2} \varepsilon_{\mathrm{n}}}-\frac{1}{2 \xi}\right) \mathrm{e}^{\frac{(1+\mathrm{i})(\xi-1)}{\sqrt{2} \varepsilon_{\mathrm{n}}}+i n \varphi}\right) \\
= & \frac{2}{R \sqrt{\xi}} \operatorname{Re}\left(\sum_{\mathrm{n}=1}^{\mathrm{N}} \tau_{\mathrm{n}}\left(\frac{1+\mathrm{i}}{\sqrt{2} \varepsilon_{\mathrm{n}}}-\frac{1}{2 \xi}\right) \mathrm{e}^{\frac{(1+\mathrm{i})(\xi-1)}{\sqrt{2} \varepsilon_{\mathrm{n}}}+i n \varphi}\right)
\end{aligned}
$$

Calculation of $\frac{\partial T}{\partial \varphi}(\xi, \varphi)$

As previously:

$$
\begin{aligned}
\frac{\partial T}{\partial \varphi}(\xi, \varphi) & \left.=\sum_{\mathrm{n}=-\mathrm{N}}^{-1}+\sum_{\mathrm{n}=1}^{\mathrm{N}}\right)\left(i n \frac{\tau_{\mathrm{n}}}{\sqrt{\xi}} \mathrm{e}^{\frac{(1+\mathrm{i})(\xi-1)}{\sqrt{2} \varepsilon_{\mathrm{n}}}+i n \varphi}\right) \\
& \left.=\frac{2}{\sqrt{\xi}} \operatorname{Re} \sum_{\mathrm{n}=1}^{\mathrm{N}} i n \tau_{\mathrm{n}} \mathrm{e}^{\frac{(1+\mathrm{i})(\xi-1)}{\sqrt{2} \varepsilon_{\mathrm{n}}}+i n \varphi}\right)
\end{aligned}
$$

\section{Appendix C}

The coefficient of the complex Fourier series can be determined from the coefficient of the real Fourier series. If we consider a function $\mathrm{f}$, the Fourier series associated to $f$ is the functions series $\sum f_{n}$ whose general term is the function $f_{n}$ defined by:

$$
\mathrm{f}_{\mathrm{n}}(\mathrm{t})=a_{\mathrm{n}} \cos (\mathrm{nt})+b_{\mathrm{n}} \sin (\mathrm{nt})
$$


With:

$$
\left\{\begin{array}{l}
a_{0}=\frac{1}{2 \pi} \int_{0}^{2 \pi} \mathrm{f}(t) \mathrm{d} t \\
a_{\mathrm{n}}=\frac{1}{\pi} \int_{0}^{2 \pi} \mathrm{f}(t) \cos (n t) \mathrm{d} t \quad \forall n \in \mathbb{N}^{*} \\
b_{0}=0 ; \quad b_{\mathrm{n}}=\frac{1}{\pi} \int_{0}^{\mathrm{T}} \mathrm{f}(t) \sin (n t) \mathrm{d} t \quad \forall n \in \mathbb{N}^{*}
\end{array}\right.
$$

$a_{0}, b_{0}, a_{\mathrm{n}}$ and $b_{\mathrm{n}}$ are the coefficients associated to the function $\mathrm{f}$.

The complex form of the development in terms of a Fourier series of a real function $\mathrm{f}$ is described by:

$\mathrm{f}(t)=\sum_{\mathrm{n}=-\infty}^{+\infty} c_{\mathrm{n}} \mathrm{e}^{i n \varphi}$

with:

$c_{\mathrm{n}}=\frac{1}{2 \pi} \int_{0}^{2 \pi} \mathrm{f}(t) \mathrm{e}^{-i n \varphi} \mathrm{d} t$

In this case, the complex Fourier coefficients $c_{\mathrm{n}}$ can be deduced from the real Fourier coefficients:

$$
\left\{\begin{array}{l}
c_{0}=a_{0} \\
c_{\mathrm{n}}=\frac{1}{2}\left(a_{\mathrm{n}}-i b_{\mathrm{n}}\right) \quad \forall n \in \mathbb{N}^{*} \text { thus: } c_{-\mathrm{n}}=\overline{c_{\mathrm{n}}}
\end{array}\right.
$$

The above remarks lead to the following relations for the Fourier coefficients $\theta_{n}$ and $\beta_{n}$ of the functions $\theta(\varphi)$ and $\beta(\varphi)$.

Calculation of $\theta_{\mathrm{n}}$ :

$$
\begin{aligned}
\theta_{0}=a_{0} & =\frac{1}{2 \pi} \int_{0}^{\varphi_{1}} \theta_{1} \mathrm{~d} \varphi+\int_{\varphi_{1}}^{2 \pi} \theta_{2} \mathrm{~d} \varphi \\
& =\frac{\theta_{1} \varphi_{1}+\theta_{2}\left(2 \pi-\varphi_{1}\right)}{2 \pi}
\end{aligned}
$$

and $\forall n \neq 0$ :

$a_{\mathrm{n}}=\frac{1}{\pi}\left(\int_{0}^{\varphi_{1}} \theta_{1} \cos (n \varphi) \mathrm{d} \varphi+\int_{\varphi_{1}}^{2 \pi} \theta_{2} \cos (n \varphi) \mathrm{d} \varphi\right)$

Thus:

$a_{\mathrm{n}}=\frac{1}{n \pi} \sin \left(n \varphi_{1}\right)\left(\theta_{1}-\theta_{2}\right)$

and:

$b_{\mathrm{n}}=\frac{1}{\pi}\left(\int_{0}^{\varphi_{1}} \theta_{1} \sin (n \varphi) \mathrm{d} \varphi+\int_{\varphi_{1}}^{2 \pi} \theta_{2} \sin (n \varphi) \mathrm{d} \varphi\right)$

Lastly, the following formulation is deduced:

$$
\begin{aligned}
b_{\mathrm{n}} & =\frac{1}{n \pi}\left(\theta_{1}\left(1-\cos \left(n \varphi_{1}\right)\right)+\theta_{2}\left(\cos \left(n \varphi_{1}\right)-1\right)\right) \\
& =\frac{1}{n \pi}\left(1-\cos \left(n \varphi_{1}\right)\right)\left(\theta_{1}-\theta_{2}\right)
\end{aligned}
$$

thus:

$\theta_{\mathrm{n}}=\frac{a_{\mathrm{n}}-i b_{\mathrm{n}}}{2}=\frac{1}{2 n \pi}\left(\theta_{1}-\theta_{2}\right)\left(\mathrm{e}^{-i n \varphi_{1}}-1\right) \mathrm{i}$

$\forall n \neq 0$

Calculation of $\beta_{n}$ for mixed Dirichlet-Neumann boundary conditions: this part concerns the case where an applied temperature is considered for the arc length in contact with the strip:

one kind of spray cooling:

$\mathrm{h}$ is taken to be the thermal exchange coefficient applied between $\left[\varphi_{1}, 2 \pi\right]$.

Note:

$$
\left\{\begin{aligned}
B=\frac{\lambda}{h} & \\
\beta_{0}=a_{0} & =\frac{1}{2 \pi}\left(\int_{0}^{\varphi_{1}} 0 \mathrm{~d} \varphi+\int_{\varphi_{1}}^{2 \pi} \frac{B}{R} \mathrm{~d} \varphi\right) \\
& =\frac{B}{2 \pi R}\left(2 \pi-\varphi_{1}\right)
\end{aligned}\right.
$$


and $\forall n \neq 0$ :

$$
\left\{\begin{array}{l}
a_{\mathrm{n}}=\frac{1}{\pi} \int_{\varphi_{1}}^{2 \pi} \frac{B}{R} \cos (n \varphi) \mathrm{d} \varphi \\
b_{\mathrm{n}}=\frac{1}{\pi} \int_{\varphi_{1}}^{2 \pi} \frac{B}{R} \sin (n \varphi) \mathrm{d} \varphi \\
\beta_{\mathrm{n}}=\frac{a_{\mathrm{n}}-i b_{\mathrm{n}}}{2}=\frac{B}{2 \pi R n} \mathrm{i}\left(1-\mathrm{e}^{-i n \varphi_{1}}\right) \quad \forall n \neq 0
\end{array}\right.
$$

Both kinds of spray cooling:

$h_{1}$ respectively $h_{2}$ is taken to be the thermal exchange coefficient applied between $\left[\varphi_{1}, \varphi_{2}\right]$ respectively between $\left[\varphi_{2}, 2 \pi\right]$.

Note:

$$
\left\{\begin{array}{l}
B_{1}=\frac{\lambda}{h_{1}} \\
B_{2}=\frac{\lambda}{h_{2}}
\end{array}\right.
$$

Then:

$$
\begin{aligned}
\beta_{0} & =\frac{1}{2 \pi R} \int_{\varphi_{1}}^{\varphi_{2}} B_{1} \mathrm{~d} \varphi+\frac{1}{2 \pi R} \int_{\varphi_{2}}^{2 \pi} B_{2} \mathrm{~d} \varphi \beta_{0} \\
& =\frac{1}{2 \pi R}\left(B_{1}\left(\varphi_{2}-\varphi_{1}\right)+B_{2}\left(2 \pi-\varphi_{2}\right)\right)
\end{aligned}
$$

Moreover:

$a_{\mathrm{n}}=\frac{1}{\pi R}\left(\int_{\varphi_{1}}^{\varphi_{2}} B_{1} \cos (n \varphi) \mathrm{d} \varphi+\int_{\varphi_{2}}^{2 \pi} B_{2} \cos (n \varphi) \mathrm{d} \varphi\right)$

and:

$b_{\mathrm{n}}=\frac{1}{\pi R}\left(\int_{\varphi_{1}}^{\varphi_{2}} B_{1} \sin (n \varphi) \mathrm{d} \varphi+\int_{\varphi_{2}}^{2 \pi} B_{2} \sin (n \varphi) \mathrm{d} \varphi\right)$
Finally, the following form is obtained:

$$
\begin{aligned}
\beta_{\mathrm{n}} & =\frac{a_{\mathrm{n}}-i b_{\mathrm{n}}}{2} \\
& =\frac{\mathrm{i}}{2 \pi R n}\left(B_{1}\left(\mathrm{e}^{-i n \varphi_{2}}-\mathrm{e}^{-i n \varphi_{1}}\right)+B_{2}\left(1-\mathrm{e}^{-i n \varphi_{2}}\right)\right) \\
& \forall n= \pm 1, \ldots \pm \mathrm{N}
\end{aligned}
$$

Calculation of $\beta_{\mathrm{n}}$ for Neumann boundary conditions: this part concerns the case where a thermal contact resistance $\left(R_{\mathrm{c}}\right)$ is considered for the arc length in contact with the strip.

Similar calculations to those considered previously provide the following results:

one kind of spray cooling:

$$
\begin{aligned}
& \beta_{0}=\frac{1}{2 \pi R}\left(\lambda R_{\mathrm{c}} \varphi_{1}+B\left(2 \pi-\varphi_{1}\right)\right) \\
& \beta_{\mathrm{n}}=\frac{\mathrm{i}}{2 \pi R n}\left(B-\lambda R_{\mathrm{c}}\right)\left(1-\mathrm{e}^{-i n \varphi_{1}}\right) \quad \forall n \neq 0
\end{aligned}
$$

Both kinds of spray cooling:

$$
\begin{aligned}
\beta_{0}= & \frac{1}{2 \pi R}\left(\lambda R_{\mathrm{c}} \varphi_{1}+B_{1}\left(\varphi_{2}-\varphi_{1}\right)+B_{2}\left(2 \pi-\varphi_{2}\right)\right) \\
\beta_{\mathrm{n}}= & \frac{\mathrm{i}}{2 \pi R n}\left(\lambda R_{\mathrm{c}}\left(\mathrm{e}^{-i n \varphi_{1}}-1\right)+B_{1}\left(\mathrm{e}^{-i n \varphi_{2}}-\mathrm{e}^{-i n \varphi_{1}}\right)\right. \\
& \left.+B_{2}\left(1-\mathrm{e}^{-i n \varphi_{2}}\right)\right) \quad \forall n= \pm 1, \ldots \pm N
\end{aligned}
$$

\section{References}

[1] C. Vergne, C. Boher, R. Gras, C. Levaillant, Wear 2006, 260, 957.

[2] R.D. Mercado-Solis, J. Talamantes-Silva, J.H. Beynon, M.A.L. Hernandez-Rodriguez, Wear 2007, 263, 1560.

[3] R. Colás, J. Ramírez, I. Sandoval, J.C. Morales, L.A. Leduc, Wear 1999, 230, 56.

[4] A.A. Tseng, F.H. Lin, A.S. Gunderia, D.S. Ni, Metall. Trans. A 1989, 20A, 2305.

[5] S.-H. Lee, G.-H. Song, S.-J. Lee, B.-M. Kim, J. Mech. Sci. Technol. 2011, 25, 2101.

[6] Y. Choi, X. Yang, J. Mech. Sci. Technol. 2012, $26,1865$. 
[7] H.-S. Park, T.-V. Anh, J. Mech. Sci. Technol. 2011, 25, 2127.

[8] E.J. Patula, J. Heat Trans. 1981, 103, 36.

[9] A.A. Tseng, J. Heat Trans. 1984, 106, 543.

[10] O.U. Khan, A. Jamal, G.M. Arshed, A.F.M. Arif, S.M. Zubair, Numer. Heat Transfer A 2004, 46, 613.

[11] H. Sheikh, Appl. Math. Model. 2009, 33, 2187.

[12] A. Pérez, R.L. Corral, R. Fuentes, R. Colás, J. Mater. Proc. Technol. 2004, 153, 894.

[13] S. Serajzadeh Inter. J. Advan. Manuf. Technol. 2008, 35, 859.

[14] S. Serajzadeh, H. Mirbagheri, A. Karimi Taheri, J. Mater. Proc. Technol. 2002, 125, 89.

[15] S.-M. Hwang, C.-G. Sun, S.-R. Ryoo, W.-J. Kwak, Comput. Method. Appl. Mech. Eng 2002, 191, 4015.

[16] A. Ktari, Z. Antar, N. Haddar, K. Elleuch, J. Mech. Sci. Technol. 2012, 26, 123.

[17] D.H. Na, S.H. Cho, Y. Lee, J. Mech. Sci. Technol. 2011, 25, 2439.

[18] W.Y.D. Yuen, J. Heat Transfer 1984, 106, 578.

[19] J. Kim, J. Lee, S.-M. Hwang, Inter. J. Heat Mass Transfer 2009, 52, 1864.
[20] C.H. Huang, T.M. Ju, A.A.Tseng, Inter. J. Heat Mass Transfer 1995, 38, 1019.

[21] R.E. Johnson, R.G. Keanini, Inter. J. Heat Mass Transfer 1998, 41, 871.

[22] A. Shirizly, J.-G. Lenard, J. Mater. Proc. Technol. 2000, 101, 250.

[23] W.-C. Chen, I.-V. Saramasekera, E.-B. Hawbolt, Metall. Trans. A Metall. Mater. Sci. 1993, 24, 1307.

[24] A.-R. Shahani, S. Setayeshi, S.-A. Nodamaie, M.-A. Asadi, S. Rezaie, J. Mater. Process. Tech. 2009, 209, 1920.

[25] S.P. Timoshenko Theory of elasticity, Mc Graw-Hill, Auckland, 1970.

[26] S.P. Timoshenko, J.N. Goodier Theory of elasticity, Mc Graw-Hill, Auckland, 1970.

[27] M. Abramowitz, I.A. Stegun, Appl. Math. Series 1972, 55.

[28] P.G. Stevens, K.P. Ivens, P. Harper, J. Iron Steel Inst. 1971, 209, 1.

[29] F.D. Fisher, W.E. Schreiner, E.A. Werner, C.G. Sun, J. Mater. Proc. Technol. 2004, 150, 263. 